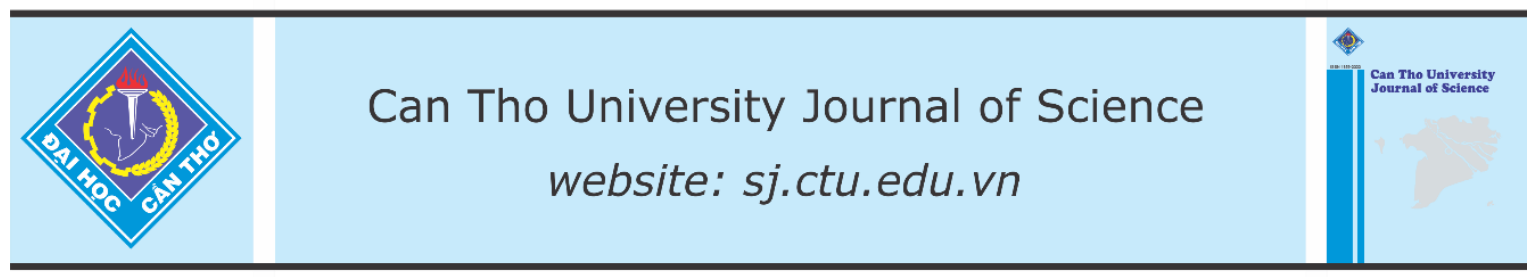

DOI: 10.22144/ctu.jen.2020.024

\title{
Adsorption of chromium (VI) ion using adsorbent derived from lignin extracted coir pith
}

\author{
Luong Huynh Vu Thanh*, Tran Nguyen Phuong Lan, Tran Thi Bich Quyen, Ha Quoc Nam and \\ Cao Luu Ngoc Hanh \\ College of Engineering Technology, Can Tho University, Vietnam \\ *Correspondance: Luong Huynh Vu Thanh (email: lhvthanh@ctu.edu.vn)
}

\section{Article info.}

Received 11 Aug 2020

Revised 08 Oct 2020

Accepted 30 Nov 2020

\section{Keywords}

Adsorbent, adsorption, $\mathrm{Cr}(\mathrm{VI})$ ion, coir pith

\begin{abstract}
In this study, coconut coir pith (cellulose-lignin compound) was first treated with water and sodium hydroxide solution to remove lignin and impurities, then lignin-extracted coir pith was calcined at $20{ }^{\circ} \mathrm{C}$ for $6 \mathrm{~h}$. The obtained adsorbent was applied to remove $\mathrm{Cr}(\mathrm{IV})$ ions by using adsorption method. Some analytical methods such as thermal gravimetric analysis (TGA), Fourier Transform Infrared Spectroscopy (FT-IR), Brunauer-Emmett-Teller analysis (BET), X-ray powder diffraction analysis $(X R D), p H_{p z c}$ analysis, Boehm titration, and potentiometric titration were employed to characterize structure, specific surface area, functional groups, and surface charge of the adsorbent. Adsorption results showed that $95.23 \%$ of $\mathrm{Cr}(\mathrm{IV})$ was removed from solution of $100 \mathrm{mg} . \mathrm{L}^{-1}$ by using a certain amount of adsorbent at pH 2.0 within 20 min at room temperature. Kinetics of $\mathrm{Cr}(\mathrm{VI})$ adsorption from aqueous solution on adsorbent fit to Pseudo-second-order kinetic equation and adsorption isotherm of $\mathrm{Cr}(\mathrm{IV})$ followed to the Freundlich model.
\end{abstract}

Cited as: Thanh, L.H.V., Lan, T.N.P., Quyen, T.T.B., Nam, H.Q. and Hanh, C.L.N., 2020. Adsorption of chromium (VI) ion using adsorbent derived from lignin extracted coir pith. Can Tho University Journal of Science. 12(3): 54-65.

\section{INTRODUCTION}

Among industrial wastewaters, electroplating effluent discharged is one of the most dangerous wastewaters, which normally contains high concentration of heavy metal ions such as $\mathrm{Cr}(\mathrm{VI}), \mathrm{Cr}(\mathrm{III})$, $\mathrm{Cu}(\mathrm{II}), \mathrm{Zn}$ (II), and $\mathrm{Ni}(\mathrm{II})$, etc. due to low yields of electroplating process (Zhao et al., 1999). Those ions are non-biodegradable, toxic, and carcinogenic, leading to an extremely environmental concern on the wastewater. Compared to other ions, $\mathrm{Cr}(\mathrm{VI})$ ions have obtained plenty of interest from researchers owing to its negative effects and commercial value (Kimbrough et al., 1999; Silva et al., 2006; Cavaco et al., 2007). From the environmental point of view, the sustainable wastewater treatment should completely recycle treated water to producing lines (Peng et al., 2004). In the case of Cr(VI) ion removal, it might be realized by adsorption using carbon derived from agricultural by-products (Tinh, 2011; Do et al., 2016), red mud (Dung et al., 2015), and distillery sludge (Selvaraj et al., 2003). Those studies reported that agricultural by-products are highly potential to remove $\mathrm{Cr}(\mathrm{VI})$ ion via their porous structure, but original adsorbents still meet their limits; hence, it is necessary to modify their surficial properties to improve the adsorption ability. 
In Vietnam, coconut coir pith (CCP) is very abundant and a by-product of coconut fiber production, causing environmental pollution in terms of water. It is a cellulose-lignin compound with low carbon content, but high surface area activated carbon can be produced from CCP (Bansal and Goyal, 2005). Santhy and Selvapathy (2004) created an adsorbent with surface area of $877 \mathrm{~m}^{2} . \mathrm{g}^{-1}$ due to the fact that the $\mathrm{CCP}$ was sunk in $\mathrm{KOH} 10 \%$ solution and calcined at $700-750^{\circ} \mathrm{C}$ before washing with $\mathrm{HCl} 10 \%$ solution. Besides, $\mathrm{CCP}$ was washed and dried under sunlight for $5 \mathrm{~h}$ before being activated with $\mathrm{ZnCl}_{2}$ at ratio of $1: 2(\mathrm{w} / \mathrm{w})$, and then calcined at $700^{\circ} \mathrm{C}$ for 1 $\mathrm{h}$. The product possessed high cationic exchange ability (1.614 mEq. $\left.\mathrm{g}^{-1}\right)$ with specific surface area of $910 \mathrm{~m}^{2} \cdot \mathrm{g}^{-1}$ (Namasivayam and Sangeetha, 2006). One study reported that CCP calcined at different temperatures of 400,600 , and $800^{\circ} \mathrm{C}$, respectively created different specific surface areas $(346,392$, and $507 \mathrm{~m}^{2} \cdot \mathrm{g}^{-1}$ ) (Namasivayam and Kadirvelu, 1997). The surface areas increased with rising calcined temperature, but carbon generated yields decreased from 60 to $55.2 \%$ as temperature increased from 400 to $800^{\circ} \mathrm{C}$ (Namasivayam and Kadirvelu, 1997). In order to reutilize CCP, the present work was conducted to produce activated carbon. The adsorbent was then applied to remove $\mathrm{Cr}(\mathrm{VI})$ ion in aqueous solution with various affecting parameters.

\section{MATERIALS AND METHODS}

All chemicals used in this work such as sodium hydroxide pellets, potassium dichromate, phosphoric acid, sodium bicarbonate were analytical reagents and purchased from Xilong Scientific. CCP was bought from Ben Tre province, Vietnam. Distilled water was used.

\subsection{Adsorbent preparation}

CCP collected was pretreated to remove tannin and lignin by sinking into water and $\mathrm{NaOH}$ solution for a desired time. CCP was first sunk in water for $24 \mathrm{~h}$ to remove tannin, and then dropped into $\mathrm{NaOH} 5 \%$ solution for $24 \mathrm{~h}$. The solid after that was washed until $\mathrm{pH}$ of the solution was neutral. The CCP was dried at $60^{\circ} \mathrm{C}$ for $48 \mathrm{~h}$ using Memmert SFE 600 dryer before calcining by Thermolyne 47900 furnace at $200^{\circ} \mathrm{C}$ for $6 \mathrm{~h}$, with the ratio of CCP to $\mathrm{H}_{3} \mathrm{PO}_{4}$ of 1:4. After calcination, the solid was sunk into $\mathrm{NaHCO}_{3} 1 \%$ solution for $12 \mathrm{~h}$ and then washed with distilled water several times to neutralize the surface of particles. Those particles were consequently dried at $60^{\circ} \mathrm{C}$ until the weight of solid was unchanged.

\subsection{Characterization of the adsorbent}

The adsorbent was characterized by using several analytical methods. TG 209 F3 Tarsus (NETZSCH) and ASAP 2020 (Micrometrics) were employed to conduct thermal gravimetric analysis (TGA) and specific surface area determination for the adsorbent. In the meantime, functional groups, morphology, and structure of the adsorbent were characterized by using Nicolet 6700 Spectrometer (Thermo Scientific), JSM 7600F (JEOL), and D8 Advance (Brucker), respectively. Boehm titration and potentiometric titration were used to determine the quantity of functional groups and the amount of charge on carbon surface.

\subsection{Adsorption experiments}

The desired amount of adsorbent was poured into a 250-mL Erlenmeyer flask containing $100 \mathrm{~mL}$ of solution with various concentrations of $\mathrm{Cr}(\mathrm{VI})$ ion. The $\mathrm{pH}$ values of solution varied from 1.0 to 8.0 while temperature of solution changed from 25 to $60^{\circ} \mathrm{C}$. A certain amount of solution was sampled at different time intervals. The concentration of $\mathrm{Cr}(\mathrm{VI})$ ion in samples was determined by using Jenway's 6800 Spectrophotometer (Keison). All experiments were triplicated. The removal yield $\mathrm{H}(\%)$ was calculated by the following equation:

$$
\mathrm{H}(\%)=\left[\frac{\mathrm{C}_{0}-\mathrm{C}_{\mathrm{t}}}{\mathrm{C}_{0}}\right] \times 100 \%
$$

Where $\mathrm{H}, \mathrm{C}_{0}$ and $\mathrm{C}_{\mathrm{t}}$ were the adsorption yield (\%), initial concentration of $\mathrm{Cr}(\mathrm{VI})$ ion $\left(\mathrm{mg} . \mathrm{L}^{-1}\right)$ and concentration of $\mathrm{Cr}(\mathrm{VI})$ ion at sampling time $\left(\mathrm{mg} \cdot \mathrm{L}^{-1}\right)$, respectively.

In this study, the adsorption model was built by using Langmuir and Freundlich isotherm models as follows:

Langmuir isotherm model:

$$
\frac{\mathrm{C}_{\mathrm{e}}}{\mathrm{q}_{\mathrm{e}}}=\frac{\mathrm{C}_{\mathrm{e}}}{\mathrm{q}_{\max }}+\frac{1}{\mathrm{q}_{\max } \mathrm{K}_{\mathrm{L}}}
$$

Freundlich isotherm model:

$$
\log q_{e}=\log K_{F}+\left(\frac{1}{n}\right) \log C_{e}
$$

where $\mathrm{q}_{\mathrm{e}}, \mathrm{K}_{\mathrm{F}}, \mathrm{n}$ and $\mathrm{C}_{\mathrm{e}}$ were mass of adsorbed ions at the equilibrium $\left(\mathrm{mg} \cdot \mathrm{g}^{-1}\right)$, the Freundlich constant, the index number of Freundlich equation, and concentration of solution at the equilibrium $\left(\mathrm{mg} . \mathrm{L}^{-1}\right)$, respectively, $\mathrm{q}_{\max }$ is described the maximum mass of adsorbed ions (mg. $\left.\mathrm{g}^{-1}\right), \mathrm{K}_{\mathrm{L}}$ is the Langmuir constant. 


\section{RESULTS AND DISCUSSION}

\subsection{Adsorbent preparation}

Table 1 showed that $20 \mathrm{~g}$ of CCP generated $10.93 \mathrm{~g}$, $10.56 \mathrm{~g}$, and $10.03 \mathrm{~g}$ of adsorbents in triplicated experiments. Consequently, the calcination yield was about $52.54 \%$ in this study. In comparison with the study of Namasivayam and Sureshkumar (1997), the carbonization yield in this work is lower by 3.0$7.0 \%$. The reasons could be that the yield was calculated based on dried weight of CCP in this work and CCP was also pretreated before carbonizing process. In the meantime, the previous study did not conduct a pretreatment experiment and calculated the carbonization yield by a ratio of carbon to dried raw material. In addition, the authors carbonized $\mathrm{CCP}$ for $1 \mathrm{~h}$ at higher temperatures $\left(400-800^{\circ} \mathrm{C}\right)$ without removing tiny particles after calcination so it could cause a slightly higher yield compared to this work.

Table 1: The yield of adsorbent preparation at $200^{\circ} \mathrm{C}$ for $6 \mathrm{~h}$ with $\mathrm{CCP}: \mathrm{H}_{3} \mathrm{PO}_{4}=1: 4(\mathrm{w} / \mathrm{v})$

\begin{tabular}{lrrr}
\hline & $\mathbf{1}^{\text {st }}$ trial & $\mathbf{2}^{\text {nd }}$ trial & $\mathbf{3}^{\text {rd }}$ trial \\
\hline Dried CCP $(\mathrm{g})$ & 20 & 20 & 20 \\
Dried adsorbent $(\mathrm{g})$ & 10.93 & 10.56 & 10.03 \\
Yield $(\%)$ & 54.66 & 52.80 & 50.16 \\
\hline Average yield (\%) & \multicolumn{3}{c}{$52.54 \pm 2.26$} \\
\hline
\end{tabular}

\subsection{Adsorbent characterization}

The adsorbent was analyzed by TGA to understand weight change, and the result was presented in Figure 1. It can be seen that when temperature increased from $30^{\circ} \mathrm{C}$ to $100^{\circ} \mathrm{C}$, the weight of adsorbent decreased by $11.17 \%$. If the temperature continuously increased to $250^{\circ} \mathrm{C}$, a decrease of the weight was $6.43 \%$. The total of $17.6 \%$ decrease in weight can be considered as moisture of adsorbent, consisting of $11.17 \%$ of water physical bonding and $6.43 \%$ of water chemical bonding. Figure 1 showed that in the range of $250-600^{\circ} \mathrm{C}$, the weight of adsorbent decreased by $28.8 \%$ due to degradation of hydrocarbon compounds into $\mathrm{CO}$ and $\mathrm{CO}_{2}$ gases. The cause of this decrease was contributed to non-complete carbonization of CCP, which occurred at relatively low temperature $\left(200^{\circ} \mathrm{C}\right)$ for $2 \mathrm{~h}$.

XRD result of adsorbent in Figure 2 showed a low intensity peak at $2 \theta=25^{\circ}-26^{\circ}$, which represented an amorphous carbon phase. Similar conclusions could be observed in reports of Das et al. (2000) and Tongpoothorn et al. (2011). Besides, no other peaks could be found in the XRD pattern, so it can be concluded that phosphoric acid or other phosphate compounds were totally removed by washing right after calcination.

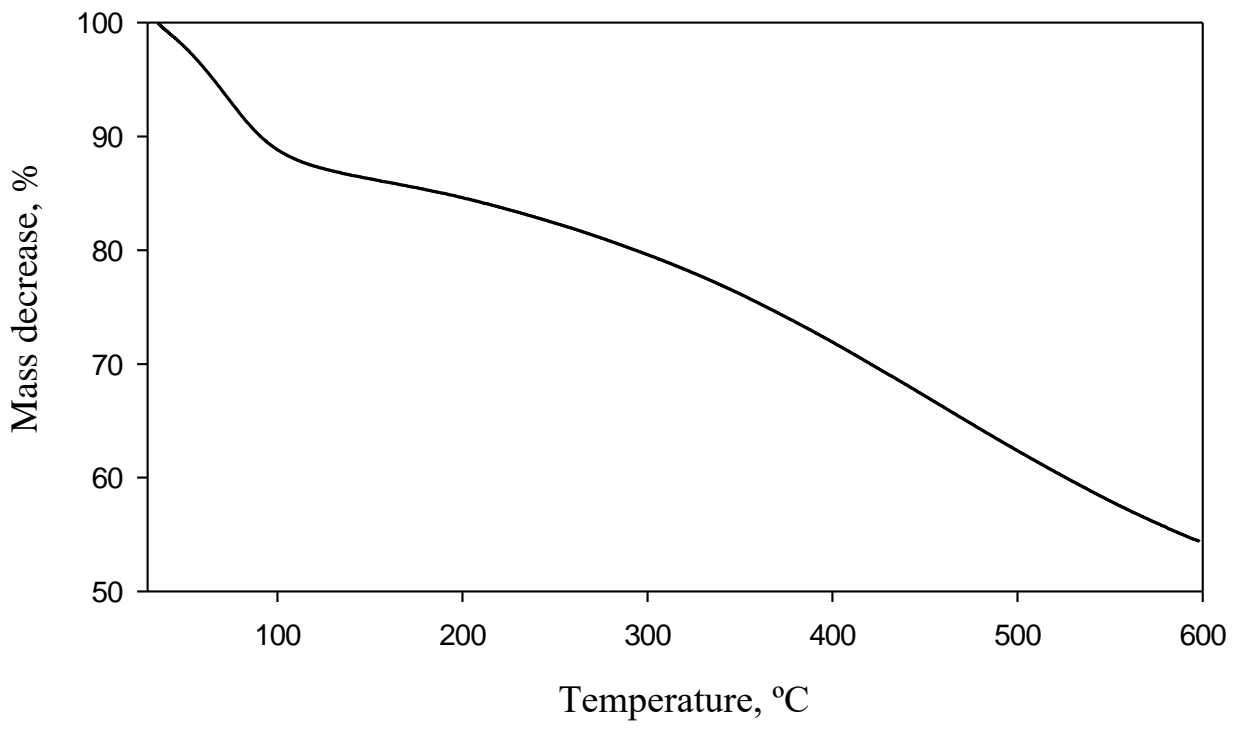

Figure 1: TGA curve of the adsorbent 


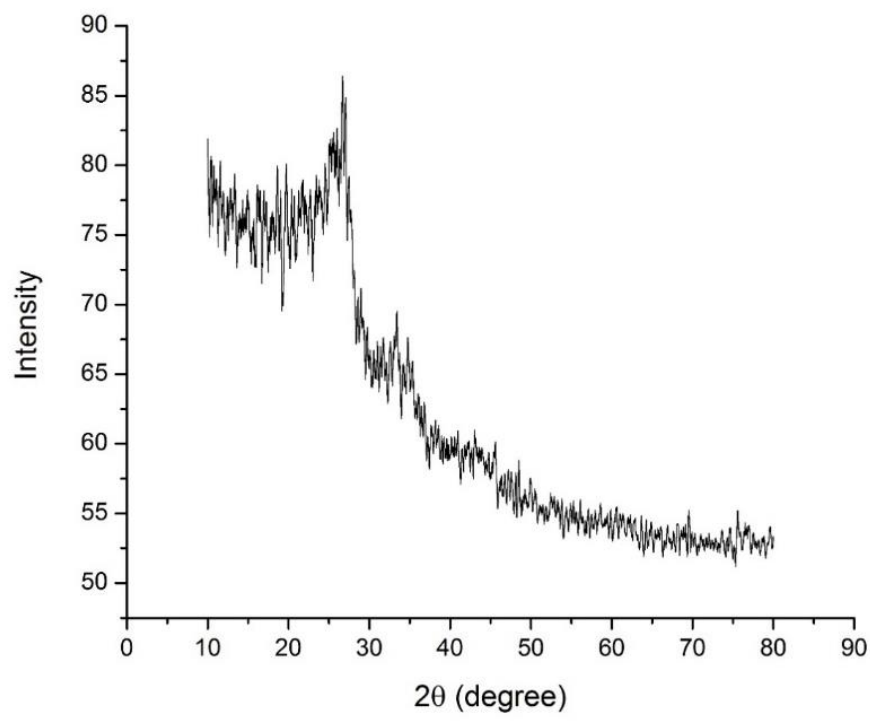

Figure 2: XRD pattern of the adsorbent

Phosphoric acid was employed in this study to carbonize CPP; thus, it could play an important role in the carbonization process. Phosphoric acid can be an acidified agent and/or functionalized agent. This was clarified by FT-IR spectra. The spectra in Figure 3 showed that peak at $3415.82 \mathrm{~cm}^{-1}$ was a broadband of -OH group, belonging to hydrogen-bonded alcohols or phenols. Stretching vibration of C-H (aromatic rings) and vibration of $\mathrm{C}=\mathrm{O}$ group (carboxylic acids or aldehydes) were bands located at $2923.57 \mathrm{~cm}^{-1}$ and $1617.40 \mathrm{~cm}^{-1}$, respectively. The $\mathrm{C}-\mathrm{O}$ stretching vibration in carboxylate groups caused the band at $1385.45 \mathrm{~cm}^{-1}$. Finally, the $\mathrm{O}-\mathrm{H}$ out-of-plane bending vibration caused the band located at $565.20 \mathrm{~cm}^{-1}$. Similar results can be found in the previous works of Bansal et al. (2009) and Yang and Qiu (2010). From all the above-mentioned groups, some positions on surface of the adsorbent were functionalized to acidic groups. In other words, carbons on the edge of adsorbent were acidified to functional groups to improve their adsorption ability, especially counter-charged solutes. No phosphate groups could be observed in FT-IR spectra of the adsorbent. It was once again concluded that phosphoric acid only played a role of acidified agent and supported carbonization agent, which could not create any bonding between phosphorus and surface of the adsorbent.

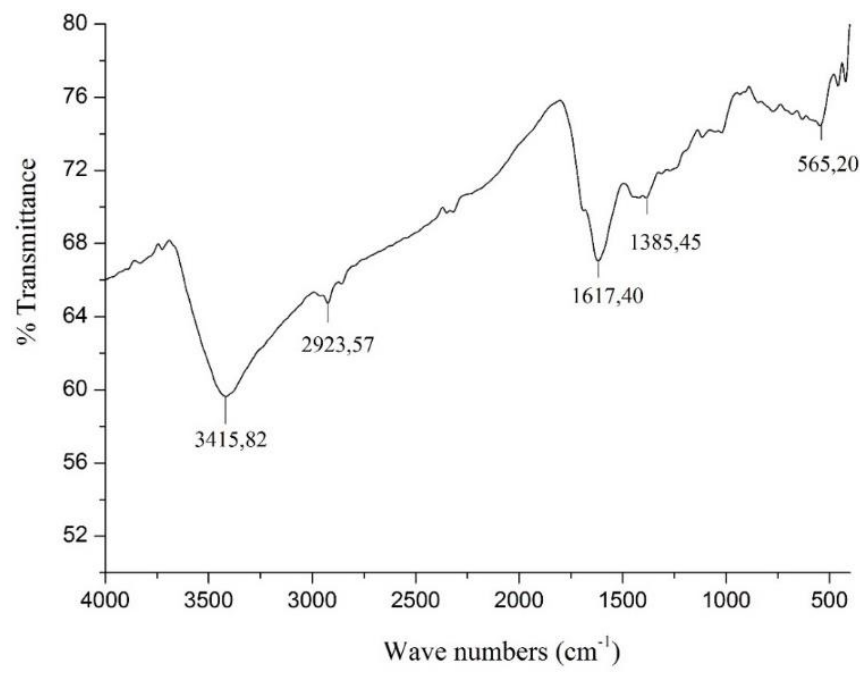

Figure 3: FTIR spectra of the adsorbent 
Result of specific surface area measurement was presented in Figure 4. It can be seen that $48.56 \mathrm{~m}^{2} . \mathrm{g}$ ${ }^{1}$ is a measured specific surface area of the adsorbent and this value is relatively low compared to 877 $\mathrm{m}^{2} \cdot \mathrm{g}^{-1}$ (Santhy and Selvapathy 2004) calcining at $700-750^{\circ} \mathrm{C}$ in presence of $\mathrm{KOH} 10 \%$ solution or 346 $\mathrm{m}^{2} \cdot \mathrm{g}^{-1}, 392 \mathrm{~m}^{2} \cdot \mathrm{g}^{-1}$, and $507 \mathrm{~m}^{2} \cdot \mathrm{g}^{-1}$ (Namasivayam and Kadirvelu, 1997) calcining at $400^{\circ} \mathrm{C}, 600^{\circ} \mathrm{C}$, and $800^{\circ} \mathrm{C}$, respectively. It could be stated that temperature greatly affects specific surface area of adsorbent obtained from calcination of CCP. The higher calcining temperature applied, the stronger carbonization of CCP happened, leading to damage of internal structure of CCP to generate more pores and improve surface area of adsorbent. In addition to surface area determination, diameter of the pores was an essential factor for adsorption treatment and adsorption selectivity of adsorbent. In this study, the average pore size of the adsorbent was $10.2 \mathrm{~nm}$. This could be considered as meso-pores, so several tens square meters per gram surface area of the adsorbent measured was reasonable.

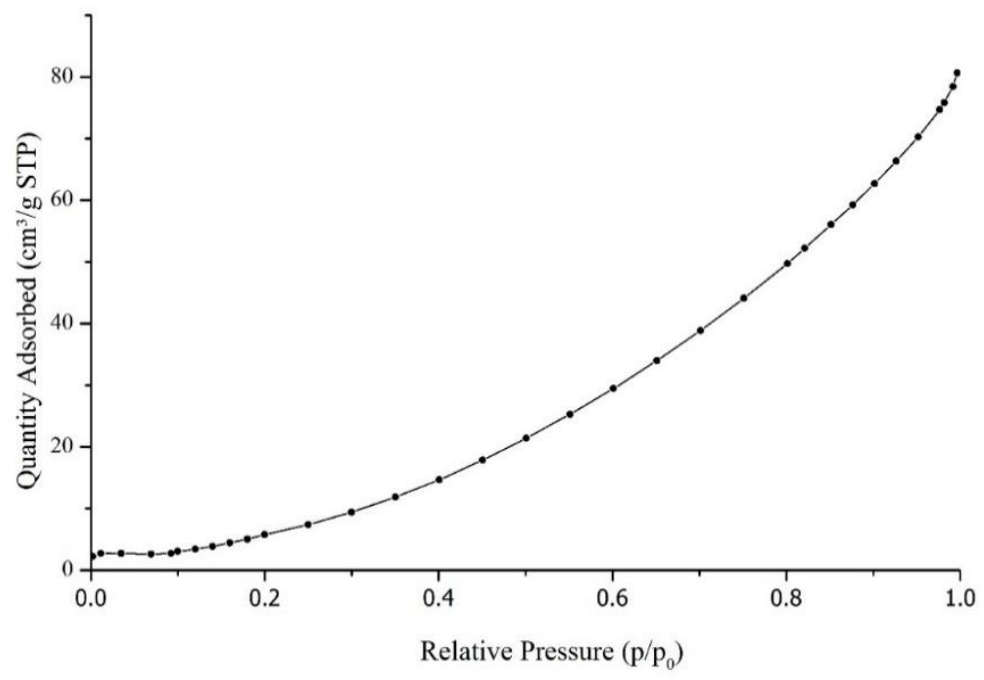

Figure 4: BET measurement of the adsorbent

Determination of acidic points on surface of adsorbent plays an essential role in prediction adsorption ability of an adsorbent. Figure 5 revealed that acidic points on adsorbent's surface were mostly neutralized after $8 \mathrm{~h}$ by $\mathrm{NaOH} 0.018 \mathrm{M}$ solution. When reaction time was kept to $24 \mathrm{~h}$, the difference in $\mathrm{NaOH}$ use was tiny. The quantity of acidic points on surface of the adsorbent using Boehm titration was calculated as $1.74 .10^{21}$ point. ${ }^{-1}$. This result was compared to the study of Dai (2000), and the difference was presented in Table 2. It can be seen that the amount of acidic points on surface of the adsorbent was 10 times higher than that of commercial activated carbon, and approximately 1.5 times com- pared to that of commercial activated carbon associated with $\mathrm{HNO}_{3}$ concentrated treatment. It illustrated that phosphoric acid helps to generate more acidic points on surface of carbon than other acids do. Finally, high amount of acidic point on surface of the adsorbent in this study could predictably benefit the adsorbent in adsorption ions in aqueous solution. Surface charge of an adsorbent is an important factor allowing to predict adsorption ability of an adsorbent at different $\mathrm{pH}$ solutions. Point of zero charge of the adsorbent was $\mathrm{pH}$ 5.7, which can be observed in Figure 6. In other words, the adsorbent could adsorb negatively charged solutes as $\mathrm{pH}$ solution was lower than 5.7, and adsorbed positively charged solutes as $\mathrm{pH}$ solution was higher than 5.7.

Table 2: Quantity of acidic points on surface of the adsorbents

\begin{tabular}{lc}
\hline & Acidic point (point.g ${ }^{-1}$ ) \\
\hline Adsorbent (this work) & $1.74 .10^{21}$ \\
Activated carbon $+\mathrm{HNO}_{3}$ conc. (heated in $4 \mathrm{~h}$ ) & $1.68 .10^{21}$ \\
Activated carbon $+\mathrm{HNO}_{3}$ conc. (heated in $\left.2 \mathrm{~h}\right)$ & $1.20 .10^{21}$ \\
Commercial activated carbon & $1.20 .10^{20}$ \\
\hline
\end{tabular}




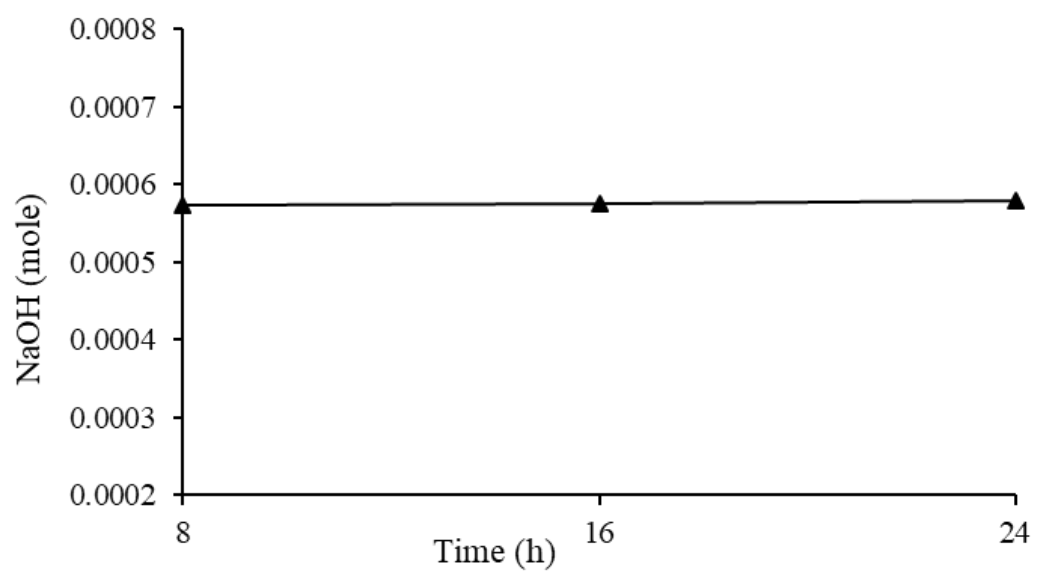

Figure 5: Boehm titration of the adsorbent

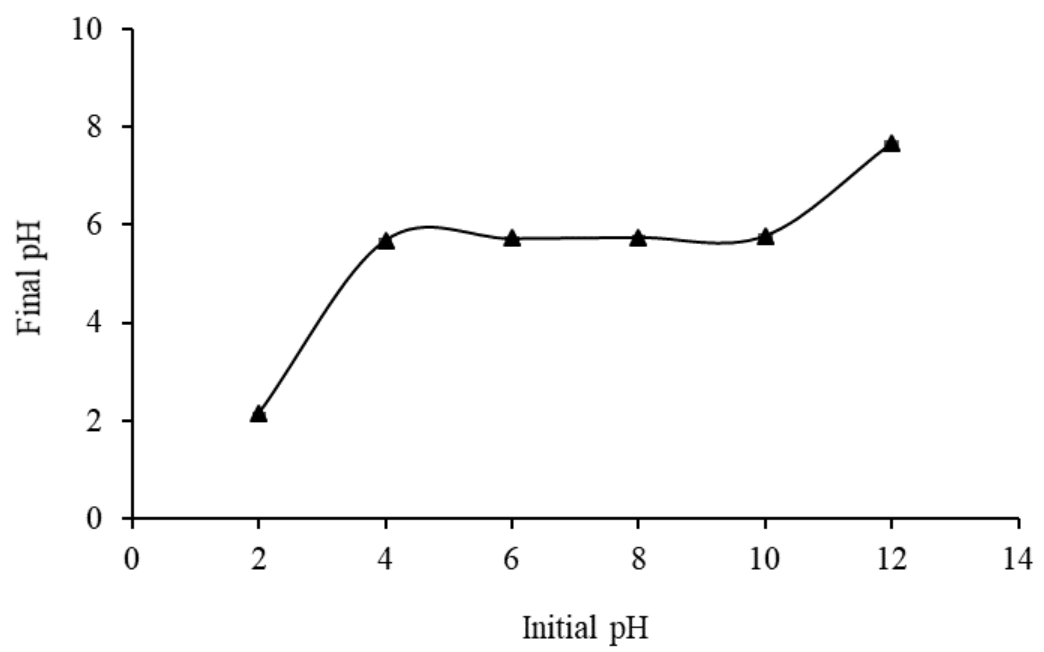

Figure 6: Potentiometric titration of the adsorbent

\section{$3.1 \mathrm{Cr}(\mathrm{VI})$ ion adsorption}

$\mathrm{pH}$ plays a vital role in adsorption of ions in aqueous solution because it determines speciation of solutes in aqueous solution. Effects of $\mathrm{pH}$ solution on adsorption yield were presented in Figure 7. When $\mathrm{pH}$ was at $1.0, \mathrm{Cr}(\mathrm{VI})$ ions removal was $99.62 \%$. It slightly decreased to $95.23 \%$ when $\mathrm{pH}$ increased to 2.0. The decrease became more significant when $\mathrm{pH}$ continuously went to neutral point. In fact, the yield decreased by $53.89 \%, 65.76 \%, 80.25$, and $79.87 \%$ when $\mathrm{pH}$ was respectively at 3.0, 4.0, 5.0 and 6.0. The lowest removal yield $(8.71 \%)$ was observed at $\mathrm{pH}$ 8.0. Those observations can be caused by the fact that increase in $\mathrm{pH}$ leads to reduce acidic points on surface of the adsorbent, and rise the quantity of $\mathrm{OH}$ group in the solution as well. Moreover, based on speciation of $\mathrm{Cr}(\mathrm{VI})$ ion presented in Figure 8, $\mathrm{Cr}(\mathrm{VI})$ ion was dominant in $\mathrm{Cr}_{2} \mathrm{O}_{7}^{2-}$ form, and small amount of $\mathrm{HCrO}_{4}^{-}$species was also observed in the $\mathrm{pH}$ range of 1.0-5.6. After $\mathrm{pH} 5.6$, the amount of $\mathrm{Cr}_{2} \mathrm{O}_{7}{ }^{2-}$ species decreased while that of $\mathrm{CrO}_{4}{ }^{2-}$ increased, and both of them obtained the same quantity at $\mathrm{pH}$ 7.2. The $\mathrm{CrO}_{4}{ }^{2-}$ species became more significant when $\mathrm{pH}$ was higher. This species reached $100 \%$ at $\mathrm{pH} 9.5$. From the above information, one $\mathrm{Cr}_{2} \mathrm{O}_{7}{ }^{2-}$ species needed two acidic points on surface of the adsorbent, but as looking carefully there were two $\mathrm{Cr}$ elements in $\mathrm{Cr}_{2} \mathrm{O}_{7}{ }^{2-}$ species; thus, one Cr element adsorbed on one acidic point of the adsorbent's surface. On the other hand, when $\mathrm{pH}$ was higher than 5.6, $\mathrm{CrO}_{4}{ }^{2-}$ appeared. Although both species possess two negative charges, $\mathrm{CrO}_{4}{ }^{2-}$ contains only one $\mathrm{Cr}$ element while the other consists of two $\mathrm{Cr}$ elements. Another important reason was that $\mathrm{pH}_{\mathrm{pzc}}$ of the adsorbent is 5.7. The surface charge of the adsorbent became less positive when $\mathrm{pH}$ increased from 1.0 to 5.7. After this point, the surface 
charge was more negative and became dominant in alkaline $\mathrm{pH}$ solution. From all above viewpoints, the change of $\mathrm{pH}$ solution from acidic to basic range caused the decrease in $\mathrm{Cr}(\mathrm{VI})$ ions adsorption on surface of the adsorbent.

Effects of contact time on $\mathrm{Cr}(\mathrm{VI})$ ion adsorption were presented in Figure 9. $\mathrm{Cr}(\mathrm{VI})$ ions were mostly removed after $90 \mathrm{~min}$. Approximate $73 \%$ of $\mathrm{Cr}(\mathrm{VI})$ was adsorbed in the first $3 \mathrm{~min}$. The removal yield increased to $95.23 \%$ when contact time was $20 \mathrm{~min}$, and then slightly rose to $96.30 \%, 98.95 \%$, and $99.23 \%$ after 30,60 , and 90 min adsorption, respectively. Based on the above result, kinetics of $\mathrm{Cr}(\mathrm{VI})$ adsorption was calculated and presented in Figure
10 and Table 3. Compared to Pseudo-first-order kinetic equation, Pseudo-second-order kinetic equation presented a good agreement to experimental results. In fact, equilibrium adsorption capacity in Pseudo-second-order equation almost equaled to practical one (331.51 mg. $\left.\mathrm{g}^{-1}\right)$ presented in Table 3. Besides, $\mathrm{R}^{2}=1$ was a strong illustration for this agreement. From the Pseudo-second-order kinetic equation, it can be seen that the slope is small $(\mathrm{a}=$ $0.0199)$. In other words, ratio $t / \mathrm{q}_{\mathrm{t}}$ was low or $\mathrm{q}_{\mathrm{t}}$ is high. High $\mathrm{q}_{\mathrm{t}}$ means a significant adsorption capacity of an adsorbent. It again confirmed that the adsorbent carbonized from CCP possesses a high adsorption capacity to $\mathrm{Cr}(\mathrm{VI})$ ions in aqueous solution at acidic $\mathrm{pH}$ solution.

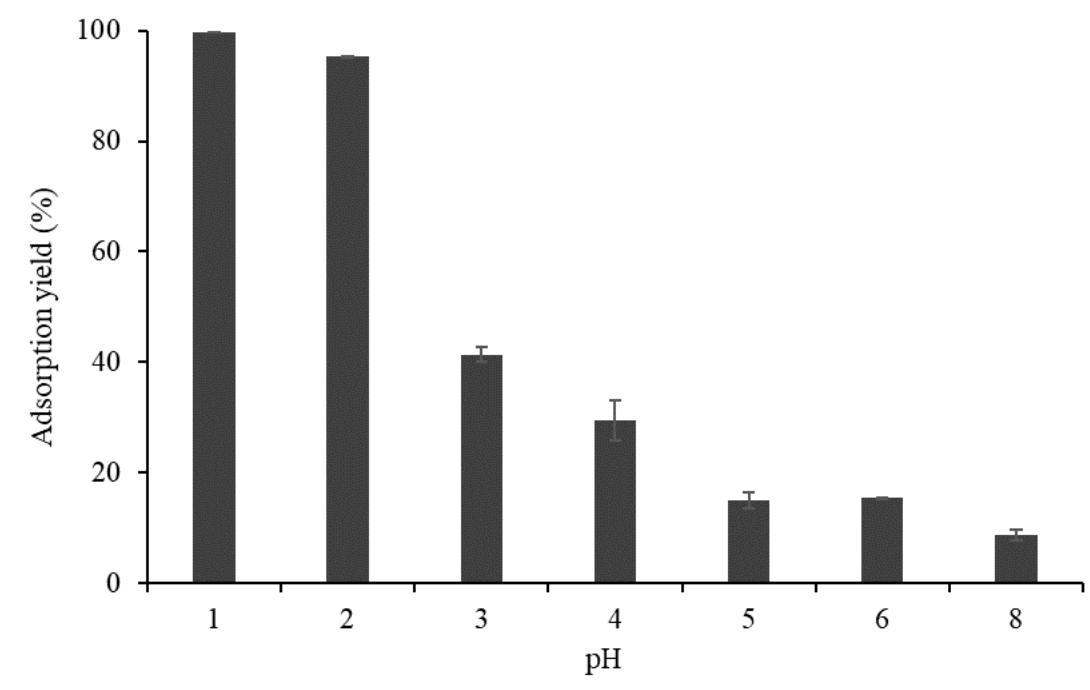

Figure 7: Effects of $\mathrm{pH}$ on $\mathrm{Cr}(\mathrm{VI})$ ions adsorption [ions concentration = $100 \mathrm{mg} . \mathrm{L}-1$; amount of adsorbent $=0.2 \mathrm{~g}$; contact time $=20 \mathrm{~min}$; stirring speed $=180 \mathrm{rpm}$; temperature $\left.=25^{\circ} \mathrm{C}\right]$

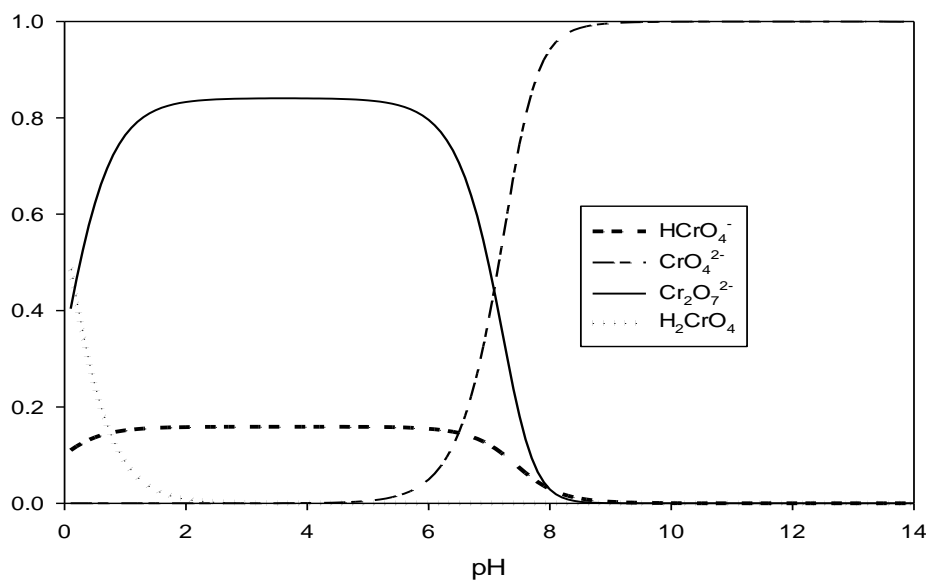

Figure 8: Speciation diagram of $\mathrm{Cr}(\mathrm{VI})$ ions with $\mathrm{pH}$ variation [2] 


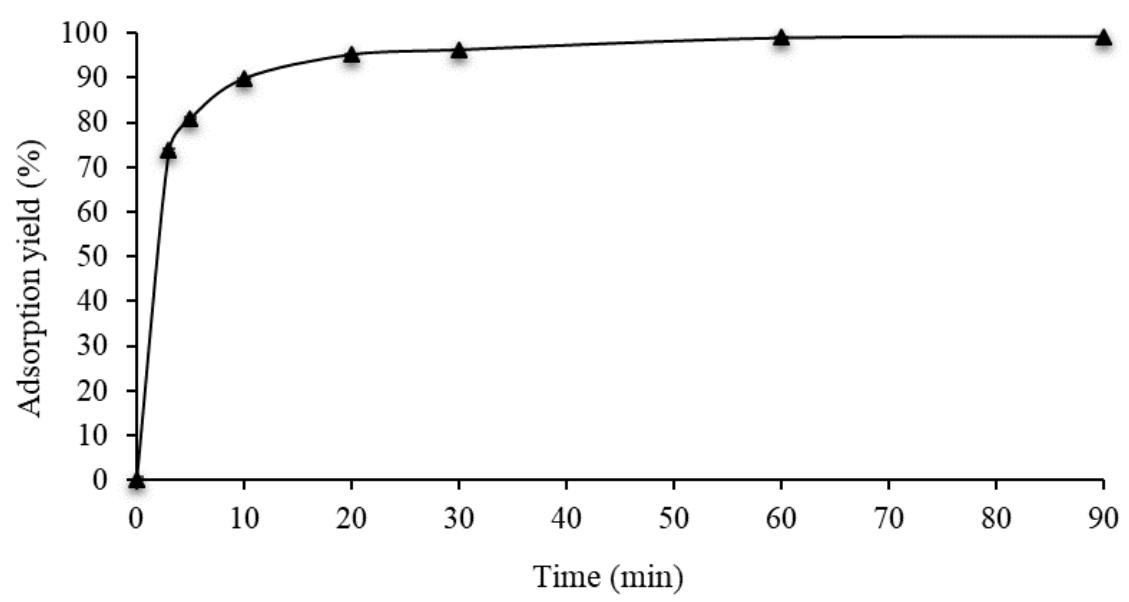

Figure 9: Effects of contact time on $\mathrm{Cr}(\mathrm{VI})$ ions adsorption [ions concentration $=100 \mathrm{mg} . \mathrm{L}^{-1}$; amount of adsorbent $=0.2 \mathrm{~g} ; \mathrm{pH} 2.0 ;$ stirring speed $=180 \mathrm{rpm}$; temperature $\left.=25^{\circ} \mathrm{C}\right]$
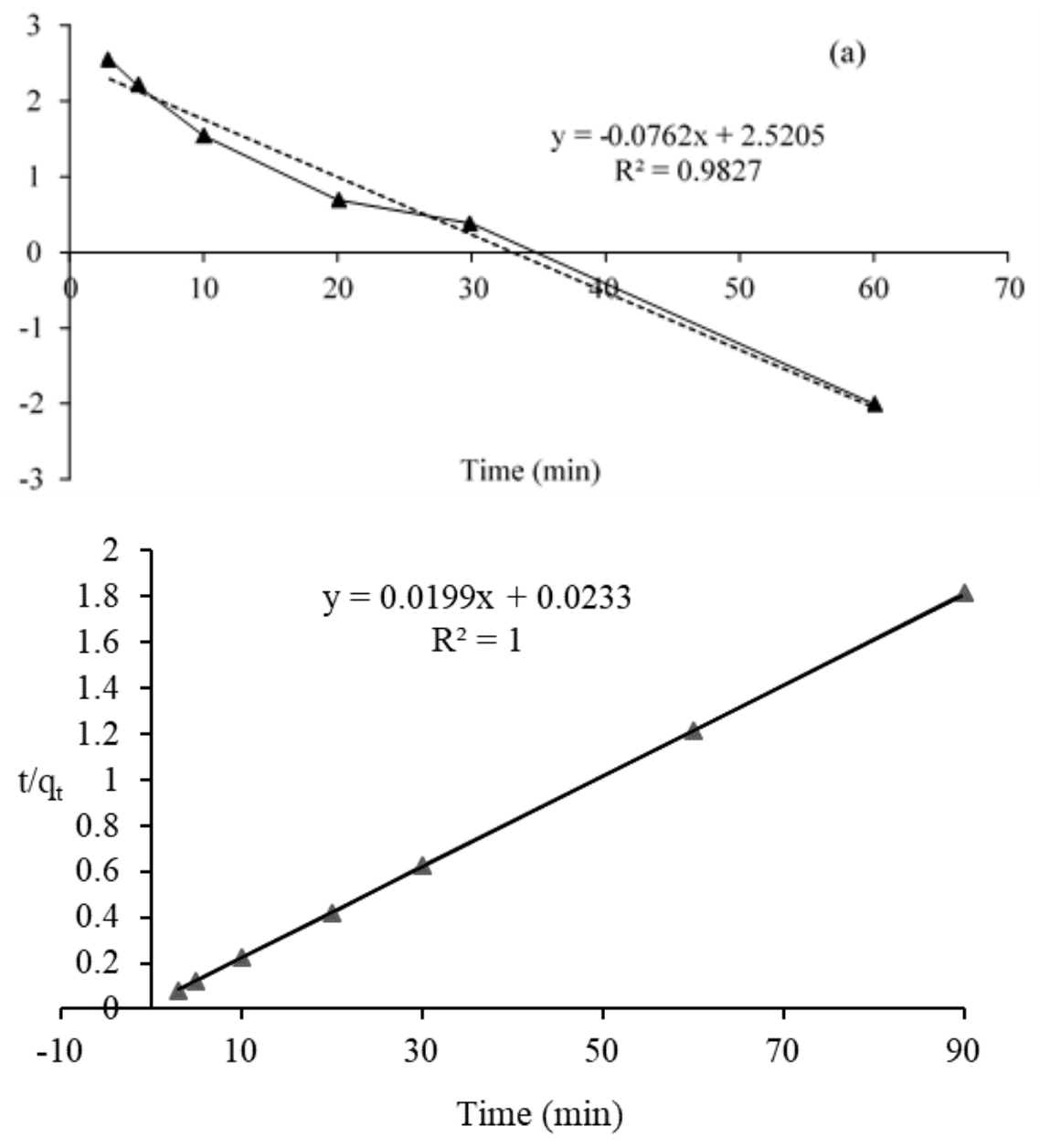

Figure 10: Kinetic plot for $\mathrm{Cr}(\mathrm{VI})$ ions adsorption: (a) Pseudo-first-order, (b) Pseudo-second-order 
Table 3: Kinetic parameters for $\mathrm{Cr}(\mathrm{VI})$ ions adsorption

\begin{tabular}{lrrrrrr}
\hline & $\mathbf{a}$ & $\mathbf{b}$ & $\begin{array}{r}\mathbf{q}_{\mathrm{e}} \\
\left(\mathbf{m g . g ^ { - 1 } )}\right.\end{array}$ & $\begin{array}{r}\mathbf{k}_{\mathbf{1}} \\
\left(\mathbf{1 . \mathbf { m i n }} \mathbf{1}^{\mathbf{1}}\right)\end{array}$ & $\begin{array}{r}\mathbf{k}_{\mathbf{2}} \\
\left(\mathbf{g} . \mathbf{m g}^{\mathbf{1}} \cdot \mathbf{m i n}^{\mathbf{1}}\right)\end{array}$ & $\mathbf{R}^{\mathbf{2}}$ \\
\hline Pseudo-first-order & -0.0762 & 2.5205 & 331.51 & -0.0762 & - & 0.9827 \\
Pseudo-second-order & 0.0199 & 0.0233 & 50.25 & - & 0.0174 & 1 \\
\hline
\end{tabular}

Table 4: Effects of initial concentrations on $\mathrm{Cr}(\mathrm{VI})$ ions adsorption

\begin{tabular}{crrr}
\hline $\begin{array}{c}\mathbf{C}_{\mathbf{0}} \\
\left(\mathbf{m g . L ^ { - 1 }}\right)\end{array}$ & $\mathbf{C}_{\mathbf{e}}\left(\mathbf{m g . L}^{-\mathbf{1}}\right)$ & Yield (\%) & $\mathbf{q}_{\mathbf{e}}\left(\mathbf{m g . g}^{\mathbf{- 1}}\right)$ \\
\hline 50 & 0.40 & $99.20 \pm 0.01$ & 24.80 \\
75 & 1.03 & $98.97 \pm 0.05$ & 36.99 \\
100 & 4.77 & $95.23 \pm 0.05$ & 47.62 \\
125 & 9.53 & $92.37 \pm 0.28$ & 57.73 \\
150 & 17.56 & $88.20 \pm 0.44$ & 66.22 \\
175 & 23.57 & $86.53 \pm 0.39$ & 75.72 \\
200 & 34.36 & $82.82 \pm 0.53$ & 82.82 \\
225 & 53.93 & $76.03 \pm 0.65$ & 85.54 \\
250 & 58.25 & $76.70 \pm 0.36$ & 95.87 \\
275 & 71.56 & $73.98 \pm 0.29$ & 101.72 \\
300 & 78.33 & $73.89 \pm 0.48$ & 110.83 \\
\hline
\end{tabular}

Initial concentration of $\mathrm{Cr}(\mathrm{VI})$ ions showed a moderate influence on adsorption performance of the adsorbent, and the results were revealed in Table 4. From Table 4, an increase of initial concentration of
$\mathrm{Cr}(\mathrm{VI})$ ions caused the relative decrease in adsorption yield, but the remarkable increase in adsorption capacity. When $\mathrm{C}_{0}$ was $50 \mathrm{mg} . \mathrm{L}^{-1}$, the yield and $\mathrm{q}_{\mathrm{e}}$ were $99.20 \%$ and $24.80 \mathrm{mg} \cdot \mathrm{g}^{-1}$, respectively. The yield decreased to $95.23 \%$ as $\mathrm{C}_{0}$ was $100 \mathrm{mg} . \mathrm{L}^{-1}$ while $\mathrm{q}_{\mathrm{e}}$ increased to $47.62 \mathrm{mg} \cdot \mathrm{g}^{-1}$ at the same initial concentration of $\mathrm{Cr}(\mathrm{VI})$ ions. A slight decrease could be observed in yield when $\mathrm{C}_{0}$ was varied from 100 to $200 \mathrm{mg} . \mathrm{L}^{-1}$ meanwhile $\mathrm{q}_{\mathrm{e}}$ showed a notable increase at identical condition. When $\mathrm{C}_{0}$ continuously increased to $300 \mathrm{mg} . \mathrm{L}^{-1}$, both yield and $\mathrm{q}_{\mathrm{e}}$ moderately varied to $73.89 \%$ and $110.83 \mathrm{mg}^{-\mathrm{g}^{-1}}$, respectively. From the above observations, it can be stated that adsorption capacity continuously increased when increasing initial concentration of $\mathrm{Cr}(\mathrm{VI})$ ions while the amount of adsorbent was kept unchanged. It implied that $\mathrm{Cr}(\mathrm{VI})$ ions adsorbed on the surface of adsorbent via multi-layer adsorption.
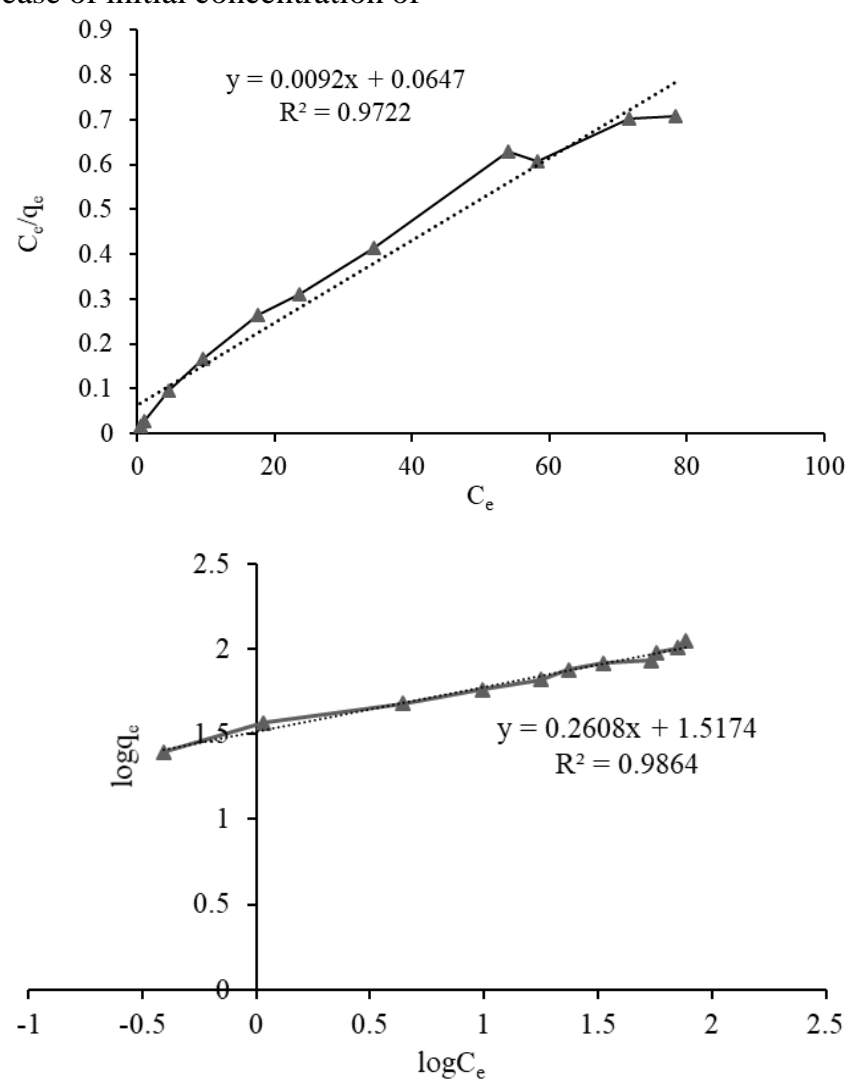

Figure 11: Adsorption isotherms plot of $\mathrm{Cr}(\mathrm{VI})$ ions (a) Langmuir, (b) Freundlich 
Adsorption isotherms of $\mathrm{Cr}(\mathrm{VI})$ ions on surface of the adsorbent were presented in Figure 11. The Freundlich isotherms model well described the experimental data in comparison of Langmuir isotherms model. In fact, $\mathrm{R}^{2}$ of the Freundlich isotherms model was 0.986 while that of Langmuir isotherms model was 0.972 . This again confirmed that multi-layer adsorption is the best model to describe adsorption of $\mathrm{Cr}(\mathrm{VI})$ ions by using the adsorbent carbonized from CCP.

To evaluate potential application of the adsorbent carbonized from CCP to remove $\mathrm{Cr}(\mathrm{VI})$ ions from aqueous solution, Table 5 might help to clarify the concern. As can be seen from Table 5, the red mud activated by sulfuric acid showed the worse $\mathrm{Cr}(\mathrm{VI})$ ions adsorption capacity, $2.34 \mathrm{mg} \cdot \mathrm{g}^{-1}$. Similar adsorption capacities can be found with cow dung activated by $\mathrm{H}_{2} \mathrm{SO}_{4}$ and $\mathrm{CCP}$ activated by $\mathrm{H}_{2} \mathrm{SO}_{4}$. RHA and tea leaves showed a remarkable increase in $\mathrm{Cr}(\mathrm{VI})$ ions adsorption capacity, namely 59.52 and $52.08 \mathrm{mg} . \mathrm{g}^{-1}$ respectively. In the comparison of such adsorbents, the adsorption capacity in this study was 2 times higher than these of RHA and tea leaves, 12 times higher than fern, and 35 times higher than $\mathrm{CCP}$ activated by $\mathrm{H}_{2} \mathrm{SO}_{4}$. It can be said that $\mathrm{CCP}$ activated by $\mathrm{H}_{3} \mathrm{PO}_{4}$ prepared in this study presented a high potential in adsorption of $\mathrm{Cr}(\mathrm{VI})$ ions.

Table 5: Adsorption capacity of adsorbents derived from various agricultural by-products

\begin{tabular}{lcrc}
\hline Raw materials & Activated agents & Activated conditions & $\mathbf{q m a x}_{\operatorname{mag}}\left(\mathbf{m g} \mathbf{g}^{-1}\right)$ References \\
\hline RHA & $\mathrm{HCHO}$ & $30^{\circ} \mathrm{C}, 5 \mathrm{~h}$ & 59.52 Tinh $(2011)$ \\
Tea leaves & $\mathrm{KOH}$ & - & 52.08 Huong et al. $(2016)$ \\
Red mud & $\mathrm{H}_{2} \mathrm{SO}_{4}$ & $80^{\circ} \mathrm{C}, 1 \mathrm{~h}$ & 2.34 Dung et al. $(2015)$ \\
Cow dung & $\mathrm{H}_{2} \mathrm{SO}_{4}$ & $120^{\circ} \mathrm{C}, 24 \mathrm{~h}$ & 4.50 Das et al. $(2000)$ \\
CCP & $\mathrm{H}_{2} \mathrm{SO}_{4}$ & $80^{\circ} \mathrm{C}, 12 \mathrm{~h}$ & 3.46 Selvi et al. $(2010)$ \\
CCP & $\mathrm{H}_{3} \mathrm{PO}_{4}$ & $200^{\circ} \mathrm{C}, 6 \mathrm{~h}$ & 110.83 This work \\
\hline
\end{tabular}

To understand nature of $\mathrm{Cr}(\mathrm{VI})$ ions adsorption by CCP activated by $\mathrm{H}_{3} \mathrm{PO}_{4}$, Temkin and D-R models were employed and the results are presented in Figure 12. The Temkin constant was calculated as $0.1621 \mathrm{~kJ}^{\mathrm{mol}}{ }^{-1}$ in Figure 12 (a). This low value presented a weak interaction between adsorbent and adsorbed, which can be considered as physical adsorption. The bonding energy between $\mathrm{Cr}(\mathrm{VI})$ ions and the calculated adsorbent via D-R model was 1.955 $\mathrm{kJ} \cdot \mathrm{mol}^{-1}$. This value was smaller than $8 \mathrm{~kJ} \mathrm{~mol}^{-1}$, meaning that the interaction between adsorbent and adsorbed in this study was physical interaction. Influences of temperature on $\mathrm{Cr}(\mathrm{VI})$ ions adsorption were shown in Figure 13. The adsorption efficiency in Figure 13 slightly increased from 92.23 to $99.16 \%$ when temperature increased from 25 to $35^{\circ} \mathrm{C}$. The change in efficiency was almost zero as long as temperature continuously increased from 35 to $60^{\circ} \mathrm{C}$. It again determined that the main mechanism of $\mathrm{Cr}(\mathrm{VI})$ ions adsorption in this study is physical interaction.

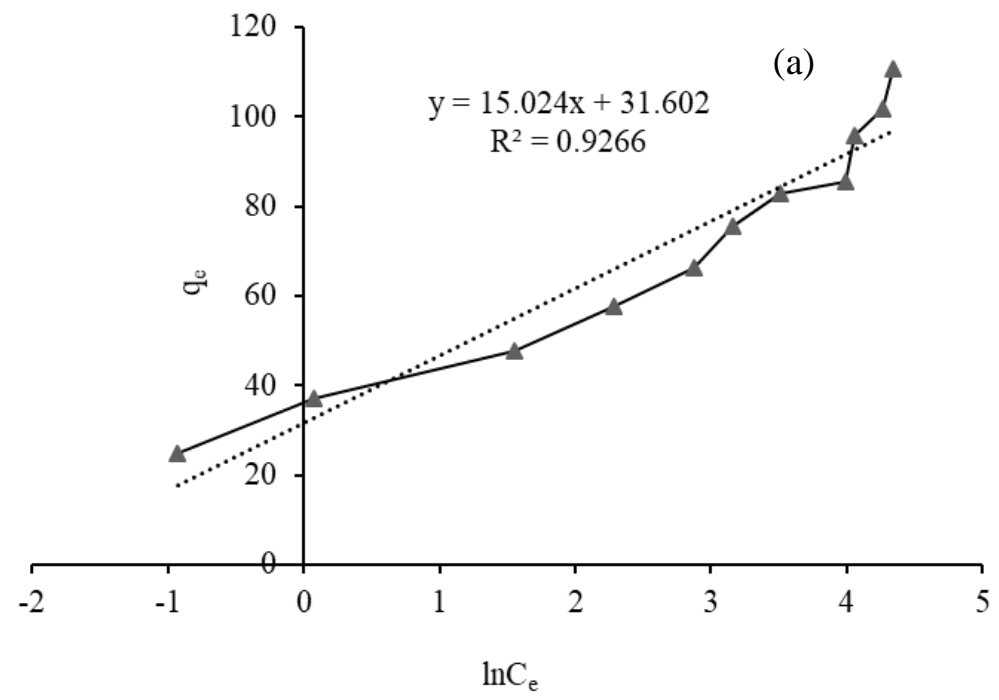




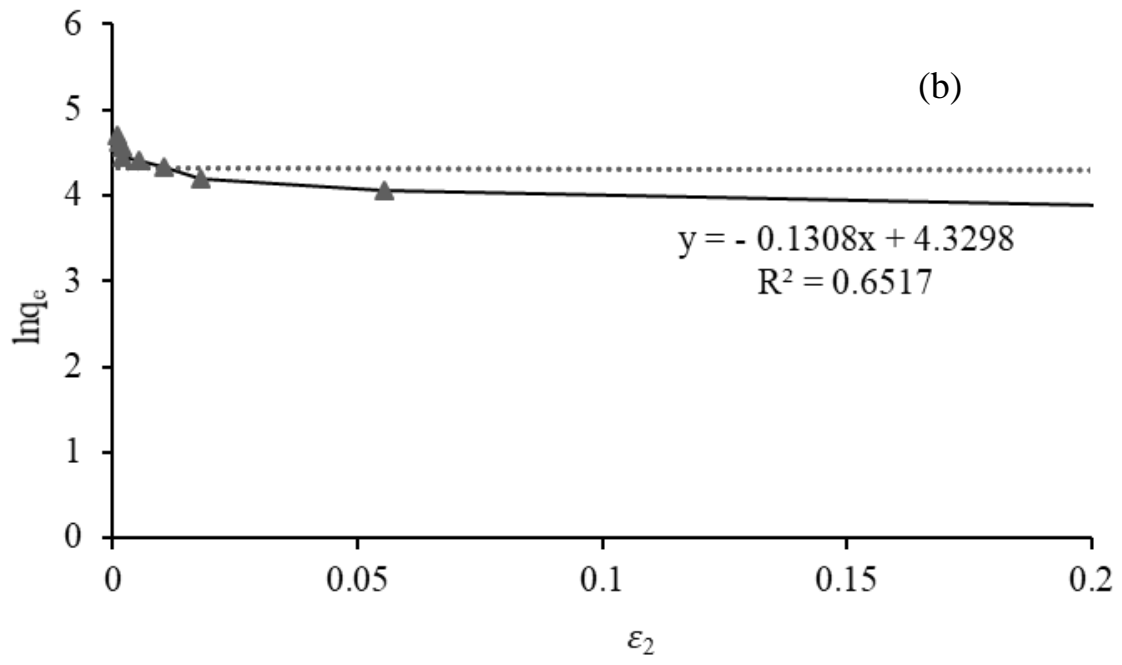

Figure 12: Sorption models for adsorption of $\mathrm{Cr}(\mathrm{VI})$ ions (a) Temkin (b) D-R

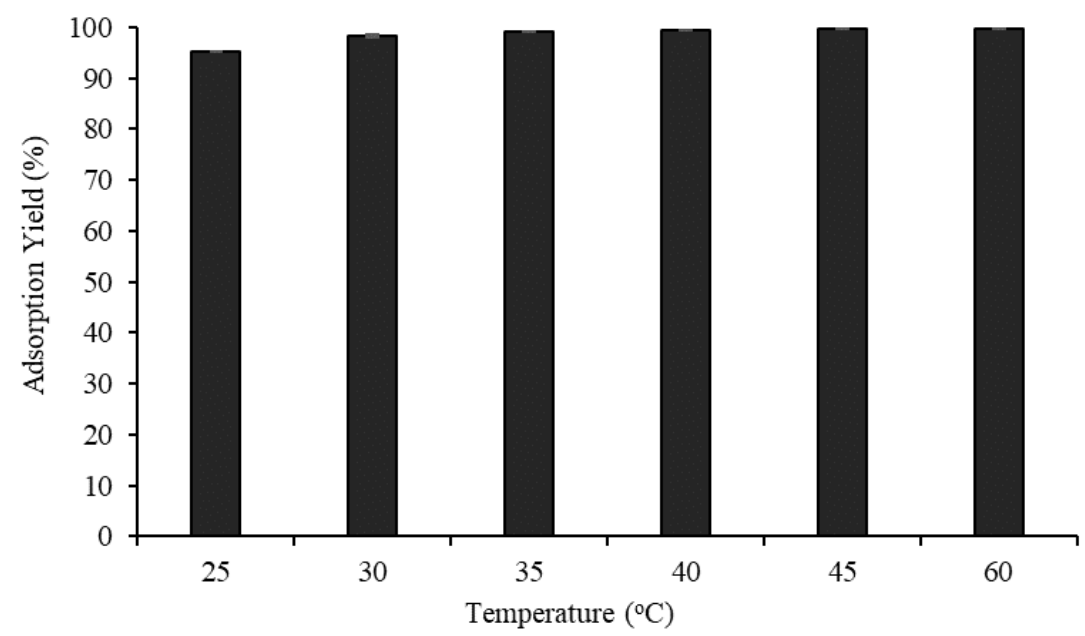

Figure 13: Effects of temperature on $\mathrm{Cr}(\mathrm{VI})$ ions adsorption [ion concentration $=100 \mathrm{mg} . \mathrm{L}^{-1}$; amount of adsorbent $=0.2 \mathrm{~g} ; \mathrm{pH} 2.0$; stirring speed $=180 \mathrm{rpm}$; contact time $=20 \mathrm{~min}]$

\section{CONCLUSIONS}

In this study, coconut coir pith was partially carbonized at temperature of $200^{\circ} \mathrm{C}$ for $6 \mathrm{~h}$ with calcination yield of $52.54 \%$. The adsorbent obtained possessed moderate surface area $\left(48.56 \mathrm{~m}^{2} . \mathrm{g}^{-1}\right)$ with pore size of $10.2 \mathrm{~nm}$, but high acidic points on the surface $\left(1.74 \quad .10^{21}\right.$ point. $\left.\mathrm{g}^{-1}\right)$. The result of potentiometric titration showed that the surface of adsorbent was positive at $\mathrm{pH}$ lower than 5.7, and negative at $\mathrm{pH}$ higher 5.7. The adsorbent was then used to adsorb $\mathrm{Cr}(\mathrm{IV})$ ions in aqueous solution. Adsorption results showed that $0.2 \mathrm{~g}$ of adsorbent adsorbed $95.23 \%$ of $\mathrm{Cr}(\mathrm{IV})$ in the solution containing $100 \mathrm{mgCr} . \mathrm{L}^{-1}$ at $\mathrm{pH} 2.0$ within $20 \mathrm{~min}$ at $25^{\circ} \mathrm{C}$. Adsorption isotherm of $\mathrm{Cr}(\mathrm{IV})$ ions and adsorption kinetics of $\mathrm{Cr}(\mathrm{VI})$ ions in aqueous solution respectively obeyed Freundlich isotherms model and Pseudo-second-order kinetic equation.

\section{REFERENCES}

Bansal, M., Singh, D. and Garg, V.K., 2009. A comparative study for the removal of hexavalent chromium 
from aqueous solution by agriculture waste' carbons. Journal of Hazardous Materials 171(1-3): 83-92.

Bansal R. C. and Goyal, M. 2005. Activated carbon adsorption, First Edition. CRC press. Boca Raton, 472 pages.

Cavaco, S. A., Fernandes, S., Quina, M. M. and Ferreira, L. M., 2007. Removal of chromium from electroplating industry effluents by ion exchange resins. Journal of Hazardous Materials 144(3): 634-638.

Das, D.D., Mahapatra, R., Pradhan, J., Das, S. N. and Thakur, R. S., 2000. Removal of Cr (VI) from aqueous solution using activated cow dung carbon. Journal of Colloid and Interface Science 232(2): 235-240.

Do Tra Huong, Dang Van Thanh, Mai Thanh Khue and Nguyen Thi Kim Ngan, 2016. Adsorption of Cr (VI) from aqueous solution using spent tea leaves modified with $\mathrm{KOH}$. Vietnam Journal of Chemistry 54: 74-80 (in Vietnamese).

Kimbrough, D.E., Cohen, Y., Winer, A.M., Creelmen, L. and Mabuni, C., 1999. A critical assessment of chromium in the environment. Critical Reviews in Environmental Science and Technology 29(1): 1-46.

Le Thi Tinh, 2011. Study of $\mathrm{Cr}$ adsorption using rice husk ash and application of $\mathrm{Cr}$ removal from wastewater, Master thesis. Can Tho University, Can Tho city (in Vietnamese).

Namasivayam, C. and Kadirvelu, K., 1997. Activated carbons prepared from coir pith by physical and chemical activation methods. Bioresource Technology 62(2): 123-127.

Namasivayam, C. and Sangeetha, D., 2006. Recycling of agricultural solid waste, coir pith: removal of anions, heavy metals, organics and dyes from water by adsorption onto $\mathrm{ZnCl}_{2}$ activated coir pith carbon. Journal of Hazardous Materials 135: 449-452.

Nguyen Tuan Dung, Vu Xuan Minh, Nguyen Thanh M and Le Thi Mai Huong, 2015. Study of activation of red mud using sulfuric acid and its adsorption with Cr (VI). Vietnam Journal of Chemistry 53: 475-479 (in Vietnamese).

Peng, C., Song, S., Lu, S. and López-Valdivieso, A., 2004. Electroplating wastewater treatment through chemical precipitation and electrodialysis. The European Journal of Mineral Processing and Environmental Protection 4(3): 210-215.

Santhy, K. and Selvapathy, P., 2004. Removal of heavy metals from wastewater by adsorption on coir pith activated carbon. Separation science and Technology 39(14): 3331-3351.

Selvaraj, K., Manonmani, S. and Pattabhi, S., 2003. Removal of hexavalent chromium using distillery sludge. Bioresource Technology 89(2): 207-211.

Selvi, K., Pattabhi, S. and Kadirvelu, K., 2001. Removal of $\mathrm{Cr}$ (VI) from aqueous solution by adsorption onto activated carbon. Bioresource Technology 80(1): 87-89.

Silva, P.T.S., Mello, N.T. and Duarte, M.M.M., 2006. Extraction and recovery of chromium from electroplating sludge. Journal of Hazardous Materials 128(1): 39-43.

Tongpoothorn, W., Sriuttha, M., Homchan, P., Chanthai, S. and Ruangviriyachai, C., 2011. Preparation of activated carbon derived from Jatropha curcas fruit shell by simple thermo-chemical activation and characterization of their physico-chemical properties. Chemical Engineering Research and Design 89(3): 335-340.

Yang, J. and Qiu, K., 2010. Preparation of activated carbons from walnut shells via vacuum chemical activation and their application for methylene blue removal. Chemical Engineering Journal 165(1): 209-217.

Zhao, M., Duncan, J.R. and van Hille, R.P., 1999. Removal and recovery of zinc from solution and electroplating effluent using Azolla filiculoides. Water Research 33(6): 1516-1522. 